\title{
Using the lever of parity of esteem between mental and physical health to close the mental health gap - a call for action
}

\author{
Sue Bailey, ${ }^{1}$ Lucy Thorpe ${ }^{2}$ and Greg Smith ${ }^{3}$
}

${ }^{1}$ President, Royal College of Psychiatrists, London, UK, Psychiatrists, London, UK,
email sbailey@rcpsych.ac.uk: Consultant Child and Adolescent Forensic Psychiatrist in the Forensic Adolescent Consultation and Treatment Service (FACTS) Greater Manchester West Mental Greater Manchester West Mental Health NHS Foundation Trust, UK; Professor, School of Social Work, University of Central Lancashire, UK

${ }^{2}$ Head of Policy Unit, Royal College of Psychiatrists, London, UK

${ }^{3}$ Policy Analyst, Royal College of Psychiatrists, London, UK
This paper provides a six-point definition of what parity of esteem for mental health means in practice. It highlights examples of the current disparity between mental and physical health and the importance of redressing this. The significance of securing a legislative basis for parity in England is discussed. The authors make a call for action, and pose six questions for international readers to consider and respond to.

A Man's body and his mind, with the utmost reverence to both I speak it, are exactly like a jerkin, and a jerkin's lining; - rumple the one - you rumple the other. (Laurence Sterne, The Life and Opinions of Tristram Shandy, Gentleman, 1761)

'The overarching principle of the parity movement is equality - in access to care, in improving the quality of care, and in the way resources are allocated' (Fritz \& Kennedy, 2012). In practice, parity between mental and physical health means (Bailey et al, 2013):

- equal access to effective, safe care

- equal efforts to improve the quality of care

- the allocation of resources on a basis commensurate with need

- equal status within healthcare education and practice

- equally high aspirations for service users; and

- equal status being given to the measurement of health outcomes.

Since the mid-20th century, most nations have signed many accords establishing that the provision of health is a fundamental human right. Health for all should be not only an aspirational target but also an essential framework for the United Nations system (Garrett et al, 2009).

We are potentially at the cusp of a new era in mental health. (Ganju, 2012)

There can be no health - and no public health - without mental health. The reported annual prevalence rate of mental health problems is as high as $38 \%$ (Wittchen et al, 2011), with mental disorders making up $13 \%$ of the disease burden and with a treatment gap of anything up to $80 \%$.

So why doesn't mental health receive the attention it deserves? Mental health problems affect every part of every country, rich and poor, across the lifespan, children, parents and grandparents, those who work and those who cannot, people with physical disabilities and those with none. It undermines the welfare of any nation and is an economic challenge, holding back prosperity. Quality of life is even more important in hard economic times, yet mental illness still remains a taboo across and within cultures. It is instinctively avoided at home, in the workplace and out in the community. When we are young, teachers and parents are unlikely to talk to us about mental illness. We all fear the unknown.

We, as mental health professionals, must shoulder some of the responsibility for failing to speak with one voice to policy makers about the potential of 'mental health global' to improve the health, well-being and resilience of populations.

\section{What happened in England - using the power of legislation}

In England mental illness represents $22.8 \%$ of the disease burden (in terms of disability-adjusted life-years, or DALYs) and accounted for $11.1 \%$ of the 2010/11 budget of the National Health Service (NHS). By way of comparison, diabetes represents $1.8 \%$ of the disease burden but accounted for $1.5 \%$ of the 2010/11 NHS budget (World Health Organization, 2004; Department of Health, 2011). Common mental disorders have 24\% treated prevalence, diabetes $94 \%$ treated prevalence (Ormel et al, 2008; McManus et al, 2009). Stigma and discrimination significantly contribute to the treatment gap (Thornicroft, 2008). Among people with a diagnosis of depression, 8 out of 10 report discrimination in at least one area of their lives (Lasalvia et al, 2013). A review of the 2004/05 research portfolios of the largest UK funders of health research indicates that mental health research received $6.5 \%$ of total funding, compared with $25 \%$ for cancer, $15 \%$ for neurological diseases and $9 \%$ for cardiovascular diseases (UK Clinical Research Collaboration, 2006).

Health professionals, including psychiatrists, were in the main opposed to the recent reform of the NHS in England. However, we used this reform as a lever to start to bring about parity, through laying bare the facts, lobbying and working with other key stakeholders and patients and carers. In consequence, included in the Health and Social Care Act 2012 (available at http://www.legislation. gov.uk) is the statement: 
the Secretary of State must continue the promotion in England of a comprehensive health service designed to secure improvement -

(a) in the physical and mental health of the people of England, and

(b) in the prevention, diagnosis and treatment of physical and mental illness.

Securing a legislative requirement for mental health to have parity with physical health offered us the opportunity we needed to drive changes in professional training and practice, attitudes and priorities in order to address the continuing inequities in healthcare provision experienced by those with mental illness.

\section{A call for action}

We need to promote a prevention paradigm mind shift. A review of research shows that half of all lifetime cases of diagnosable mental illness, other than dementia, have begun by the age of 14 (Kessler et al, 2007; Shiers \& Kendall, 2012). There is evidence that improved availability of earlyintervention services for children and for young people could prevent up to $50 \%$ of mental illness (Kim-Cohen et al, 2003).

We need to prevent people from dying prematurely when they have mental illness.

We need to enhance the quality of life of people with long-term conditions across psychiatry, neurology and geriatric medicine.

We need to help people to recover from episodes of ill health and to ensure that people have a positive experience of the health services provided in any country.

We need to treat and care for people in a safe environment and to protect them from harm.

We need to play our part as professionals to promote innovative ways to integrate care, and to engage with patients and their families.

\section{Specific challenges and emerging solutions}

Many of the causes of the premature mortality and excess morbidity associated with mental illness - for example smoking and obesity, which, for a combination of reasons, are both common among people with mental illness - are avoidable (Thornicroft, 2011). Why are people with mental illness less likely to be offered smoking cessation interventions, despite being more likely to smoke than people without mental illness and being just as motivated to quit (Phelan et al, 2001; Siru et al, 2009; McManus et al, 2010)? We can bring about change, for example by improving the cardiovascular health of young people with severe mental illness, thereby addressing an epidemic within an epidemic (Bailey et al, 2012).

\section{Psychiatrists as leaders for change}

Psychiatrists as doctors should lead in enabling zero tolerance of discrimination, comprehensive mental health training for all healthcare staff, the promotion of direct contact with service users which destigmatises mental illness, and the adoption of an approach based on human rights
(Pettigrew \& Tropp, 2006), with a focus on equality, dignity and respect (Curtice \& Exworthy, 2010). This can also improve clinical outcomes. Systemic underrepresentation should be measured by comparing actual service usage with population incidence and demography; also, a recovery ethos should be adopted in all the work we undertake.

\section{In conclusion}

The long-standing and continuing lack of parity between mental and physical health remains inequitable and socially unjust. It breaches the fundamental human right of people with mental health problems to the highest attainable standard of health. The poorer outcomes that result are considered by many, both within and outside mental healthcare, to be all that can be expected. To tackle this we need to move beyond the field of mental health legislation and look for opportunities across all legislation as it relates to education, social care, employment, justice and minority rights.

For example, the United Nations Committee on Economic, Social and Cultural Rights in its most recent report on the UK's adherence to the Convention on Economic, Social and Cultural Rights states that, in relation to article 12 - the commitment to recognise the right of everyone to the enjoyment of the highest attainable standard of physical and mental health - people with mental health problems experienced 'significantly poorer health conditions' than those without (United Nations, 2009, p. 9).

At a global level, the recent 65th World Health Assembly highlighted the global scale of mental health problems and the need for a comprehensive, coordinated response from health and social care sectors at the country level. That response was to include 'equitable access to affordable, quality and comprehensive health services that integrate mental health into all levels of the health-care system' (World Health Assembly, 2012).

A rallying call for a worldwide parity approach can deliver healthier nations with improved wellbeing but, more importantly, those with physical and mental health problems will be able to sustain and maintain resilience to cope with whatever adversity life throws at them. This is achievable through interventions that can save money, in both the short and the longer term, and this should be music to the ears of ministers of finance, health, justice, education, and employment (Knapp et al, 2011).

To progress this work, we are asking all readers to respond to the following questions, in relation to your country and area of expertise:

- What is your view of the main challenges involved in achieving parity between mental and physical health? (These might include a lack of understanding of the concepts, direct opposition to the concepts, stigma, cultural issues and patients' and carers' experiences of physical health specialists.)

- Could you provide us with real examples of good parity initiatives from your country, 
including but not confined to vulnerable groups of patients, or within the population?

- Have you experienced any particular legislative barriers or enablers in relation to parity, beyond health legislation? (Examples might include welfare reform, the criminal justice system, education, immigration and asylum.)

- From your perspective, what does 'good' look like? (For example, people with mental health disorders would have the same physical health outcomes as people without them.)

- What are the organisational barriers and enablers, whether in local government or in your part of the healthcare system?

- What, in your view, are the financial, cultural, structural, educational (undergraduate/postgraduate/continuing professional development, etc.) and technological implications of delivering parity of esteem for mental health?

Please address your responses to Greg Smith (gsmith@rcpsych.ac.uk). Together we can make a difference.

\section{References}

Bailey, S., Gerada, C., Lester, H., et al (2012) The cardiovascular health of young people with severe mental illness: addressing an epidemic within an epidemic. Psychiatrist, 36, 375-378.

Bailey, S., Thorpe, L. \& Smith, G. (2013) Whole-Person Care: From Rhetoric to Reality. Achieving Parity Between Mental and Physical Health (Occasional Paper OP88). Royal College of Psychiatrists. Curtice, M. J. \& Exworthy, T. P. (2010) FREDA: a human rightsbased approach to healthcare. Psychiatrist, 34, 150-156. Department of Health (2011) National expenditure data 2003-04 to 2010-11. Available at https://www.gov.uk/government/uploads/ system/uploads/attachment_data/file/156133/dh_131856.xls.xls (accessed July 2013)

Fritz, G. K. \& Kennedy, P. J. (2012) The long road ahead to mental health parity. Journal of the American Academy of Child and Adolescent Psychiatry, 51, 458-460.

Ganju, V. (2012) Non-communicable diseases and the menta health gap: what is to be done? International Psychiatry, 9, 79-80. Garrett, L., Chowdhury, A. M. R., Pablos-Méndez, A. (2009) All for universal health coverage. Lancet, 374, 1294-1299.

Kessler, R. C., Amminger, G. P., Aguilar-Gaxiola, S., et al (2007) Age of onset of mental disorders: a review of recent literature. Current Opinion in Psychiatry, 20, 359-364.

Kim-Cohen, J., Caspi, A., Moffitt, T. E., et al (2003) Prior juvenile diagnosis in adults with mental disorder: developmental follow-back of a prospective longitudinal cohort. Archives of General Psychiatry, $60,709-717$.
Knapp, M., McDaid, D. \& Parsonage, M. (2011) Mental Health Promotion and Mental Illness Prevention: The Economic Case. Department of Health.

Lasalvia, A., Zoppei, S., Van Bortel, T., et al (2013) Global pattern of experienced and anticipated discrimination reported by people with major depressive disorder: a cross-sectional survey. Lancet, 381, 55-62.

McManus, S., Meltzer, H., Brugha, T., et al (2009) Adult Psychiatric Morbidity in England, 2007. Results of a Household Survey. Health and Social Information Centre, Social Care Statistics.

McManus, S., Meltzer, H. \& Campion, J. (2010) Cigarette Smoking and Mental Health in England: Data from the Adult Psychiatric Morbidity Survey. National Centre for Social Research.

Ormel, J., Petukhova, M., Chatterji, S., et al (2008) Disability and treatment of specific mental and physical disorders across the world. British Journal of Psychiatry, 192, 368-375.

Pettigrew, T. F. \& Tropp, L. R. (2006) A meta-analytic test of intergroup contact theory. Journal of Personal and Social Psychology, 90, 751-783.

Phelan, M., Stradins, L. \& Morrison, S. (2001) Physical health of people with severe mental illness. BMJ, 322, 443-444.

Shiers, D. \& Kendall, T. (2012) Tackling a scandal of premature mortality; time for a 'hearts \& minds' approach. LSE Health and Social Care blog, 6 July, http://blogs.Ise.ac.uk/ healthandsocialcare/2012/07/06/tackling-a-scandal-of-prematuremortality-time-for-a-hearts-minds-approach/ (accessed July 2013).

Siru, R., Hulse, G. K. \& Tait, R. J. (2009) Assessing motivation to quit smoking in people with mental illness: a review. Addiction, 104 719-733.

Sterne, L. (1761) The Life and Opinions of Tristram Shandy, Gentleman (eds M. New \& J. New), vol. 3, ch. 4. University of Florida Press $(1978)$

Thornicroft, G. (2008) Stigma and discrimination limit access to mental health care. Epidemiologica e Psichiatrica Sociale, 17, $14-19$

Thornicroft, G. (2011) Physical health disparities and mental illness: the scandal of premature mortality. British Journal of Psychiatry $199,441-442$

UK Clinical Research Collaboration (2006) UK Health Research Analysis. UKCRC.

United Nations (2009) Concluding Observations of the Committe on Economic Social and Cultural Rights: United Kingdom of Great Britain and Northern Ireland, the Crown Dependencies and the Overseas Dependent Territories. UN.

Wittchen, H. U., Jacobi, F., Rehm, J., et al (2011) The size and burden of mental disorders and other disorders of the brain in Europe 2010. European Neuropsychopharmacology, 21, 655-679.

World Health Assembly (2012) Ninth plenary meeting, 25 May 2012. WHA65.4. Agenda item 13. Available at http://www who. int/mental_health/WHA65.4_resolution.pdf (accessed June 2013).

World Health Organization (2004) Death and DALY Estimates for 2004 by Cause for WHO Member States. WHO. Available at http:// www.who.int/healthinfo/global_burden_disease/estimates_country/ en/index.html (accessed June 2013).

THEMATIC PAPERS

Behavioural and Brain Sciences Unit, Institute of Child Health, London, UK, email d.skuse@ ucl.ac.uk

\title{
Conflict and mental health in North Africa and the Middle East
}

\author{
David Skuse
}

Conflict in the Middle East and in North Africa has consistently made headlines over the past 2 years for one reason or another. Yet despite the extensive coverage of slaughter and mayhem, little has been said about the destruction of the infrastructure supporting medical services, and even less about the psychiatric consequences of conflict. There is growing evidence of deteriorating mental health of the general population in affected countries, among both those who stay and the burgeoning 